\title{
Desenvolvimento sustentável "made in Quebec". Políticas de proteção ao meio ambiente e biotecnologias ${ }^{1}$
}

GILLES BIBEAU"

\begin{abstract}
Para entrar no século XXI, impõe-se um paralelo com o século XVI: era o início da modernidade, estamos na pós-modernidade. (...) Sobreviver à ciência é reconhecer que ela não nos torna deuses: o princípio de precaução reintroduz o sentido do humanismo na pós-modernidade.

Jean-Jacques Salomon, Survivre à la science. Une certaine idée du futur, Paris: Albin Michel, 1999: quarta capa.
\end{abstract}

\section{Resumo}

Sob um certo ângulo, os avanços técnico-científicos permitiram-nos "domesticar" a natureza. Este ensaio propõe-se a levantar a situação das políticas ambientais governamentais, principalmente no Quebec, que adotou em abril de 2006 a lei sobre o desenvolvimento sustentável. Nessa linha argumentativa, considero as mudanças no contexto dos recentes avanços das biotecnologias, que nos conferem sobretudo poderes até recentemente desconhecidos sobre a natureza, a vida e o ser humano. As diversas formas de intervenção dos governos do Canadá e do Quebec revelam um nítido crescimento da presença ativa do Estado, não somente nos setores tradicionais, mas também na bioindústria, onde o governo intervém cada vez mais. Os desafios, consequências e questões dessa realidade serão tratados sob a ótica de um novo humanismo.

Palavras-chave: Quebec. Biotecnologias. Políticas ambientais. Humanismo.

1 Tradução de Patrícia Chittoni Ramos Reuillard (UFRGS).

* Professor titular, Universidade de Montreal. Montreal H3C 3J7. gilles.bibeau@sympatico.ca 


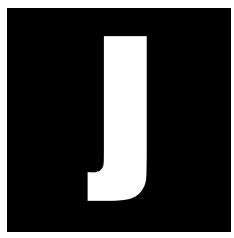

ean-Jacques Salomon ${ }^{2}$ foi um pensador e, ao mesmo tempo, um homem de ação que procurou "consertar" os excessos de alguns grandes avanços científicos, principalmente aqueles ligados aos explosivos, que nos permitiram, é verdade, domesticar melhor a natureza e colocá-los ao nosso serviço; entretanto, fomos arrastados para uma indústria da guerra, sem cessar alimentada por explosivos cada vez mais potentes. Logo após a aposentadoria em sua casa de campo no vilarejo de Banyuls, sul da França, Salomon engajou-se em uma associação local que buscou reunir artistas e cientistas com o objetivo de "reabilitar" a antiga fábrica de dinamite criada pelo físico Alfred Nobel em Paulilles, vilarejo vizinho de Banyuls. Ao transformar a fábrica de explosivos em um museu dedicado à paz, seu objetivo era demonstrar os laços sutis que sempre levam a conviver "culturas da guerra" e "culturas da paz", destruição do ser humano e progressos técnicos.

Nas reflexões deste ensaio, proponho levantar a situação das políticas ambientais governamentais, mais particularmente no Quebec, considerando-as no contexto dos recentes avanços das biotecnologias, que

2 Dedico este ensaio a Jean-Jacques Salomon (1929-2008), um dos maiores pensadores humanistas de nossa pós-modernidade técnico-científica. Titular, durante inúmeros anos, da cátedra de Tecnologia e Sociedade no Conservatoire National des Arts et Métiers de France, meu amigo Jean-Jacques representa, para mim, a figura do cientista rigoroso e consciencioso que não deixou de lançar um olhar crítico, lúcido e frequentemente irônico sobre nossa "civilização de altos riscos" (título do último livro que ele nos deixou como herança). Ele fez isso, interrogando o status das tecnociências em nossas sociedades do saber que são também sociedades profundamente ancoradas em uma ideologia neoliberal do desenvolvimento, e avaliando os riscos relacionados ao poder de nossas biotecnologias que são, hoje em dia, capazes de transformar a natureza e de recriá-la de certo modo, modificando os genomas das plantas, dos animais, até mesmo dos próprios seres humanos. Acima de tudo, Jean-Jacques preocupou-se com o lugar ocupado pela bioindústria na via econômica de nossos países e com a competição neoliberal feroz que joga as bioeconomias umas contra as outras em um mundo globalizado onde a conquista de novos mercados é imperativa. Não é surpreendente que o livro predileto de J.-J. Salomon tenha sido "Guerra e Paz", de Tolstoi, um livro ao qual ele retorna constantemente e com propriedade, em um grande número de suas próprias obras. 
nos conferem poderes até recentemente desconhecidos sobre a natureza, a vida e o ser humano. Tratarei destes assuntos, dedicando-me ao lugar que os laços entre meio ambiente, desenvolvimento sustentável e bioindústria ocupam nos trabalhos dos cientistas sociais e no pensamento da população em geral. Em um primeiro momento, descreverei o contexto de adoção da lei quebequense sobre o desenvolvimento sustentável, em abril de 2006, para satisfação de numerosos grupos progressistas da sociedade civil quebequense, inclusive de grupos ambientalistas sérios, que a saudaram como uma iniciativa positiva. Levantarei, entretanto, algumas questões sobre a "seriedade" do envolvimento de nosso governo quando adotou essa lei, que não parece ter realmente iniciado, a meu ver, uma autêntica virada na filosofia quebequense do desenvolvimento.

Considerando que faz pouco tempo que os quebequenses dão mostras de uma sólida conscientização ecológica, interrogarei como essa sensibilidade crescente à fragilidade de nossos ecossistemas se coaduna com o fato de habitarmos um imenso território com ecossistemas altamente diversificados e desenvolvermos uma poderosa economia nacional largamente apoiada na exploração dos recursos naturais (pensemos na floresta, nas minas e nas barragens, de onde tiramos quase toda nossa eletricidade). É bem possível que o discurso sobre o desenvolvimento sustentável e o respeito aos meios ecológicos seja desmentido, na prática, pela exploração intensa dos recursos naturais, um dos trunfos da economia do Quebec.

Também me perguntarei por que os sociólogos, antropólogos e outros especialistas dos fenômenos sociais demoraram tanto para se abrir às questões ambientais e por que é tão pequena, ainda hoje, a presença dos especialistas das Ciências Sociais praticadas no Quebec nos debates públicos sobre os diferentes problemas relacionados ao meio ambiente; são igualmente poucos a questionar a ajuda maciça que nosso governo dá à bioindústria, através de uma grande variedade de programas que subsidiam biotecnolo- 
gias desenvolvidas, entre outros, em torno da proteção de transgênicos, cada vez mais encontrados nos campos dos agricultores quebequenses.

Como um fio condutor que permeia esses questionamentos, eu me perguntarei se o Quebec consegue, ou pode conseguir, por em prática a filosofia do desenvolvimento sustentável que escolheu, no contexto de sua indústria de exploração dos recursos naturais, de sua floresta, de seus rios e de seu solo rico em minerais. Para além das relações com a natureza, são nossas relações com a vida e com o ser humano que estão em jogo no uso abundante de nossos ecossistemas, sem que verdadeiras críticas surjam da população civil.

\section{Desenvolvimento sustentável "made in Quebec"}

Assim como em outras regiões do globo, a província do Quebec está cada vez mais preocupada com o aquecimento global e com outros problemas ambientais, e essas questões são consideradas pelo governo do ponto de vista da filosofia do desenvolvimento sustentável. O Quebec tem consciência dos problemas associados ao crescimento econômico, cujas repercussões se estendem bem além de suas fronteiras territoriais: diminuição das fontes de energia fóssil, aumento dos gases de efeito estufa, proliferação das matérias residuais, redução da capacidade de suporte dos ecossistemas, alastramento urbano, desigualdades sociais e econômicas persistentes são apenas alguns exemplos.

Sob a pressão dos especialistas, dos grupos ambientalistas e da sensibilidade crescente dos cidadãos, os políticos quebequenses iniciaram uma virada, ao menos retórica, para uma política que agora prevê um crescimento econômico que leve em conta recursos cada vez mais limitados, desigualmente repartidos tanto entre países quanto entre indivíduos, antecipando custos de utilização dos produtos (principalmente a energia) 
que ultrapassarão muito o valor que pagamos hoje e contabilizando as consequências (efeitos perversos) da transformação das matérias primas sobre o meio ambiente. A transição para a durabilidade assim iniciada exige uma transformação profunda das mentalidades e da maneira de agir e uma reflexão que ainda não se fez realmente acerca do tipo de vida desejável e aceitável nas sociedades atuais, tanto no Norte quanto no Sul.

O Ministério do Desenvolvimento Sustentável, do Meio Ambiente e dos Parques, criado em 2007 após a adoção da lei sobre o desenvolvimento sustentável, tem a missão de velar para que todos os ministérios e órgãos governamentais se inspirem e trabalhem para realizar os objetivos inscritos na Estratégia Governamental do Desenvolvimento Sustentável 2008-2013, elaborada em dezembro de 2007. O Conselho da Ciência e da Tecnologia (CST) e a Comissão de Ética da Ciência e da Tecnologia (CEST), ligadas ao ministério do Desenvolvimento Econômico, da Inovação e da Exportação, foram as primeiras instituições quebequenses a elaborar Planos de Ação (2008-2011), inspiradas, segundo dizem, na filosofia do desenvolvimento sustentável.

Na qualidade de órgão consultivo criado em 1983 pela Lei sobre o Desenvolvimento Científico e Tecnológico do Quebec (sucedeu ao Conselho da Política Científica, que existia desde 1971), o CST tem a missão de propor ao ministério planos integrados, rigorosos e críticos, que visem desenvolver, respeitando o meio ambiente, a ciência, a tecnologia e a inovação em benefício da sociedade quebequense. Essa missão guia uma visão sistêmica do papel da ciência, da tecnologia e da inovação na vida econômica do Quebec, sobretudo quando se trata da exploração da floresta, dos rios e do subsolo; o CST deve também avaliar os pontos fortes e fracos das atividades técnico-científicas e seu impacto sobre o meio de vida dos cidadãos, sobre seus hábitos e sobre o meio ambiente em geral.

A CEST, criada em 2001, embora ligada administrativamente ao CST, goza de total independência na execução de sua missão - suscitar a refle- 
xão e os debates sobre as questões éticas levantadas pelas atividades científicas e pelas diferentes aplicações das tecnociências, principalmente as biotecnologias. Essa missão comporta, na realidade, dois compromissos: o primeiro consiste em informar, sensibilizar, receber opiniões, suscitar a reflexão e organizar os debates sobre as questões éticas do desenvolvimento da ciência e da tecnologia; ao segundo cabe propor orientações passíveis de guiar os atores envolvidos em suas tomadas de decisão. A Comissão de Ética define por sua própria iniciativa seus objetos de intervenção ou responde às prioridades do ministro ou às solicitações do Conselho.

Nos últimos anos e em parceria com outros órgãos, o CST participou de medidas envolvendo a participação cidadã a fim de levantar, nas consultas ao grande público e à comunidade universitária, a demanda social de novos saberes capazes de vencer os desafios sociais, culturais e econômicos maiores que a sociedade quebequense deverá enfrentar nas próximas décadas. Essa medida originou o projeto Perspectives STS (ciência, tecnologia e sociedade), cujas temáticas, em número de sete, estão vinculadas diretamente aos princípios de desenvolvimento sustentável e de proteção do meio ambiente: promoção de hábitos saudáveis de vida com vistas a uma abordagem preventiva em saúde; maior eficácia do sistema de saúde; gestão dos recursos naturais e do desenvolvimento sustentável; acesso universal a uma formação de alta qualidade; determinação dos nichos estratégicos e prioritários para o desenvolvimento econômico do Quebec; energias novas e renováveis; e medidas inovadoras na luta contra a pobreza.

Por sua vez, a CEST destacou, em conformidade com sua missão, vários princípios de desenvolvimento sustentável que coincidem com aqueles examinados pelo CST: saúde e qualidade de vida, prevenção, produção e consumo responsáveis, acesso cidadão ao saber, participação cívica e envolvimento, equidade e solidariedade sociais, eficácia econômica, proteção ao meio ambiente, preservação da biodiversidade e respeito à capacidade de suporte dos ecossistemas, e questões de equidade e de solidariedade 
sociais. Dentre os temas que a CEST tratou ao longo dos últimos anos, podem-se mencionar, a título de exemplo, as questões éticas levantadas pela gestão dos transgênicos, os bancos de informação genética, as nanotecnologias e a doação e o transplante de órgãos; todos esses temas são fortemente ligados ao desenvolvimento da bioindústria quebequense.

Como prevê a Lei sobre o Desenvolvimento Sustentável, as produções do CST e da CEST devem contribuir para a integração do desenvolvimento sustentável nas políticas, programas e ações do governo em matéria de ciência, de tecnologia e de inovação, de modo a garantir que o desenvolvimento da bioindústria não venha a contradizer os princípios básicos da política de desenvolvimento sustentável. Devido ao olhar crítico lançado pelo CST e pela CEST sobre o desenvolvimento das tecnociências e das biotecnologias e seus impactos sobre as diferentes formas de vida, esses dois órgãos são continuamente levados a considerar os impactos sociais, econômicos, ambientais e éticos do desenvolvimento da ciência e da bioindústria.

Na prática, é bem possível que as perspectivas estabelecidas pelo CST e pela CEST visem mais a criar condições para o avanço, no Quebec, da indústria dos recursos naturais e da bioeconomia do que velar pela proteção do meio ambiente tal como preconizado na filosofia do desenvolvimento sustentável. Devido à sua missão de informação e de sensibilização, o Conselho e a Comissão ocupam uma posição privilegiada para alimentar o debate sobre as questões relativas ao desenvolvimento sustentável em matéria de ciência, tecnologia e inovação e para incitar a consideração dos princípios do desenvolvimento sustentável nas ações governamentais. O CST e a CEST podem igualmente propor medidas para conciliar desenvolvimento econômico e desenvolvimento sustentável.

Em um relatório apresentado, em setembro de 2009, à Comissão dos Transportes e do Meio Ambiente, os grupos ambientais Equiterre e Funda- 
ção David Suzuki manifestaram sua inquietação com as ações do governo, principalmente no que tange à inadequação (inexistência, na verdade) dos indicadores criados para verificar o alcance dos objetivos visados pela lei. Nem o CST nem a CEST jamais dedicaram um único relatório ou um único parecer a essa questão, no entanto fundamental, dos indicadores de avaliação do impacto das atividades, inclusive das atividades técnico-científicas, sobre o meio ambiente. Do mesmo modo, nunca o princípio de precaução, tão caro aos países europeus, foi reconhecido como um princípio indissociável do desenvolvimento sustentável: canonizando o princípio de precaução, o desenvolvimento da bioindústria teria sido prejudicado.

Todavia, deve-se reconhecer que o governo do Quebec defende, por intermédio do CST e da CEST, um diálogo entre a ciência e a tecnologia, de um lado, e a sociedade quebequense e sua economia, de outro. Ele declara almejar que o Quebec possa se transformar em uma verdadeira sociedade do saber, que a ciência e a tecnologia possam se apoiar, para seu desenvolvimento, nas esferas públicas e privadas da pesquisa e da inovação e nos parceiros do desenvolvimento socioeconômico. É nesse contexto que as instituições governamentais querem assistir ao surgimento de uma verdadeira sociedade do saber, com alto nível geral de cultura científica e tecnológica, e de uma poderosa economia baseada nos avanços das tecnociências.

Com o intuito de contribuir para a aproximação entre a ciência, a tecnologia e a sociedade, o Conselho e a Comissão de Ética propõem dar maior atenção à manifestação das expectativas, inquietações e temores da população, vinculando-se, assim, ao princípio de participação e de envolvimento dos cidadãos. As preocupações sociais ligadas ao desenvolvimento econômico e à bioindústria constituem uma importante questão sobre a qual se debruçam o CST e a CEST, embora sem examiná-la do ponto de vista dos princípios do desenvolvimento sustentável. A lei sobre 
o desenvolvimento sustentável foi considerada uma alavanca que permite o avanço das tecnociências, enquanto vela, por meio de algumas balizas éticas, para que sejam mais limpas, mais eficazes e mais suscetíveis de levar a um melhor bem-estar. Todavia, nem sempre os trabalhos do CST e da CEST conseguiram conciliar desenvolvimento sustentável e crescimento econômico, tema que deveria ser o foco de suas preocupações. Talvez tenham se dedicado demais a criar as condições favoráveis para que o Quebec pudesse melhorar seu desempenho e vantagem concorrencial em sua bioindústria.

O que dizer desta frase, no mínimo surpreendente, do Plano de Ação do Desenvolvimento Sustentável 2008-2011 do CST: "Os membros do Conselho e da Comissão de Ética já se mostram, aliás, muito sensíveis aos princípios do desenvolvimento sustentável no cotidiano. Assim, mais da metade dos funcionários utilizam o transporte ativo ou o transporte coletivo para se dirigir ao trabalho. Além disso, a coleta seletiva das matérias residuais já está em vigor nas dependências de trabalho. Esforços estão sendo feitos para reduzir o consumo de papel; privilegia-se a impressão frente-verso" (CST, 2002, p.6).

Lendo os documentos governamentais relativos ao desenvolvimento sustentável, tem-se a impressão de que a adoção desse conceito esvaziou grande parte de seu conteúdo. O que. Salomon escreveu acerca do "imperialismo do progresso" se aplica muito bem ao Quebec, que se apropriou da retórica vigente do desenvolvimento sustentável sem perceber todas suas implicações. Salomon escreve: "Há ironia e até desdém - e por que não, mais vale dizer, hipocrisia - na noção de desenvolvimento sustentável. É exatamente por isso que ela parece convir tão bem hoje em dia a todos os espíritos, tanto de direita como de esquerda, mesmo àqueles que a reivindicam como um desejo irrealizável para servir-se dela e lucrar com ela" (Salomon, 2005, p. 137). 


\section{Tensões entre bioeconomia, desenvolvimento sustentável e respeito ao meio ambiente}

O campo de aplicação das biotecnologias é extenso, pois engloba saúde, produção agrícola e processos industriais, principalmente em química, e tem inúmeras implicações institucionais, políticas (via regulamentação e propriedade intelectual), econômicas e éticas. A OCDE acaba de dedicar um importante relatório ao futuro do vasto complexo da "bioeconomia", tomando como meta o ano de 2030 (OCDE, 2009). Os autores do relatório salientam que, em 2005, a biotecnologia mal representava 1\% do PIB dos países da OCDE e que essa porcentagem continua crescendo desde então. As potencialidades desse setor são claramente superiores às de outros setores; porém, o relatório observa que o futuro da bioindústria dependerá dos progressos técnicos e científicos (rapidez do mapeamento dos genomas, transferência dos genes, possibilidades da biologia sintética e da bioinformática) e das respostas que as tecnociências darão aos grandes desafios mundiais, sobretudo ao aquecimento climático, às fontes energéticas do mundo sem petróleo, às crises alimentares e aos problemas sanitários.

A OCDE propõe duas tendências maiores no desenvolvimento das bioeconomias: de um lado, uma forte penetração das biotecnologias na produção agrícola ( $76 \%$ da soja, $44 \%$ do algodão e $20 \%$ do milho serão geneticamente modificados em 2015); de outro, um aumento da presença dos biocombustíveis e das biotecnologias na indústria, passando a produção química por procedimentos biotecnológicos de 2\% em 2005 a 25\% em 2030 nos países da OCDE. A parcela relativa das biotecnologias no PIB desses países poderá triplicar entre 2005 e 2030 e ser maior em países em desenvolvimento, tais como a China, a Índia e o Brasil. O número de medicamentos provenientes das biotecnologias também deverá aumentar, principalmente graças a novas técnicas de diagnóstico, ao crescimento da farmacogenética e da medicina preditiva (caso das doenças 
de origem genética) e regenerativa (regeneração de tecidos corporais com células-tronco). A área da saúde poderá oferecer as perspectivas mais interessantes, com os transgênicos em agricultura e os biocombustíveis como fonte alternativa de energia. Os especialistas da OCDE acreditam que a produção agrícola, a química e os biocombustíveis poderão criar, dentro de pouco tempo, mercados mais promissores que os da farmácia.

Nesse relatório, a OCDE questiona a perenidade do modelo industrial desenvolvido em torno das biotecnologias: diante do custo crescente dos gastos em P\&D na farmácia e dos gastos de saúde, o modelo institucional e industrial atual mostra-se cada vez menos "sustentável". Assim, para evitar que a bioindústria fique sem saída, a OCDE considera uma transição para dois outros modelos: um "cooperativo" e um "integrado". O modelo cooperativo se desenvolveria a partir de uma divisão por subsetor (a saúde, por exemplo) dos conhecimentos técnico-científicos e, eventualmente, de uma co-propriedade das patentes (por meio de pools), que implicaria a criação de consórcios de institutos públicos de pesquisa, empresas privadas e órgãos de saúde. Em um sistema integrado, seriam criadas empresas ou consórcios, integrando as funções de P\&D e de produção para gamas específicas de produtos (os biocombustíveis, por exemplo).

Na prática, o Canadá e a Província do Quebec - esta primeiro - já se engajaram nessas duas formas de especialização da bioindústria. A OCDE ilustra a problemática da bioeconomia com diversos cenários de crise possíveis: fim da abundância do capital-risco, epidemias de gripe ameaçando a saúde pública, secas provocando crises alimentares mundiais. Essas crises poderiam provocar, por exemplo, um aumento dos biocombustíveis e dos cultivos transgênicos, o que acarretaria uma reestruturação do modelo industrial e institucional que hoje prevalece na bioindústria. Ora, conforme constata o relatório da OCDE, atualmente não há mais adequação entre os gastos públicos e privados em P\&D e as perspectivas 
dos mercados para os produtos biotecnológicos: a pesquisa pública e privada no campo das biotecnologias aplicadas à saúde domina bastante o setor das biotecnologias (representa $80 \%$ dos gastos em P\&D), enquanto a OCDE estima que $75 \%$ das aplicações futuras serão nos setores agrícola e industrial, excetuando a farmácia.

A OCDE propõe que as políticas públicas dêem maior importância às aplicações das biotecnologias à agricultura e à indústria, o que já se faz no Canadá e no Quebec. Ela ressalta também a necessidade de nos prepararmos para mudanças maiores em nossos sistemas de saúde se quisermos enfrentar as crises de financiamento, mudanças que implicarão negociação contínua entre os governos, empresas, cientistas e cidadãos. Esse relatório considera o futuro das biotecnologias com um otimismo prudente e, embora persistam algumas zonas de sombra (discutem-se pouco as questões de ética e de propriedade intelectual e estão ausentes as considerações ecológicas), ele tem o mérito de promover uma reflexão estratégica sobre a bioeconomia, cujos avanços maiores talvez não se encontrem no setor da saúde, conforme numerosos relatórios de prospectiva recentes parecem afirmar. As políticas públicas e industriais deverão, desse modo, redefinir suas prioridades caso se queira evitar que os grandes laboratórios farmacêuticos, cujos medicamentos podem se tornar demasiado custosos, conheçam a mesma sorte que a General Motors (Vidal e Bibeau, 2009). O Quebec, cuja bioindústria é fortemente organizada em torno dos laboratórios farmacêuticos, deveria considerar esse parecer.

As diversas formas de intervenção dos governos do Canadá e do Quebec revelam um nítido crescimento da presença ativa do Estado, não somente nos setores tradicionais, mas também na bioindústria, onde o governo intervém cada vez mais, em nome da criação de empregos de alto nível, de uma maior competitividade das economias canadense e quebequense em um sistema capitalista mais protecionista do que verdadeiramente glo- 
balizado e, enfim, em nome da necessidade de modernizar a sociedade, que não deve deixar escapar, segundo nos dizem, a virada tecnológica e todas as vantagens econômicas que ela pode trazer para nosso país. Não compreendo como alguns especialistas em Ciências Políticas ainda podem falar, com seriedade, de um recuo do Estado, até mesmo de seu desaparecimento em decorrência da globalização das economias nacionais.

É necessário encontrar o nicho certo, onde a empresa possa se impor em uma bioindústria competitiva hoje globalizada, dispor de uma forte capitalização para sustentar as atividades de P\&D e se aliar aos melhores parceiros em pesquisas complexas, campo em que a cooperação entre laboratórios e entre companhias tornou-se a regra. Fusões, desfusões, parcerias, acordos - eis o que doravante une e desune, em montagens audaciosas, as companhias de biotecnologia, as multinacionais farmacêuticas, as empresas privadas de pesquisa, as universidades e os governos.

A P\&D está mais do que nunca tomada, na indústria das biotecnologias, por considerações políticas, econômicas, comerciais e jurídicas: tal é situação do Canadá, sobretudo do Quebec, e ainda mais de Montreal, cujas bioindústrias, generosamente subsidiadas pelo Estado quebequense, demonstram um dinamismo extraordinário, único no espaço canadense. "Montreal, futura capital mundial da genômica-proteômica?", afirma-se em todo o Canadá e no exterior. Neste país, as macroforças do mercado da bioindústria se revelam cada vez mais poderosas, até mesmo invasivas, e contribuem, sobretudo graças aos acordos que regulamentam o comércio internacional, para consolidar um pouco mais a cada dia a posição hegemônica dos países ocidentais, principalmente da América do Norte, no campo das biotecnologias e da indústria farmacêutica.

Doravante parece ser impossível separar as atividades de P\&D da bioindústria, tanto nas empresas privadas quanto na universidade, da busca dos interesses e do lucro das empresas transnacionais em uma 
economia globalizada e amplamente submetida às regras criadas pelos países mais industrializados, do contexto jurídico criado pelos acordos em matéria de comércio internacional, de expedição das patentes e de proteção das marcas, e, enfim, do apoio financeiro que os Estados mais ricos dão às companhias instaladas em seu território. Lembro que a Organização Mundial do Comércio (OMC) concedeu aos Estados o direito de subsidiar, dentro de certos limites, a produção agrícola e as empresas industriais a fim de torná-las mais competitivas no mercado internacional.

Mais do que qualquer outra área do saber, as biotecnologias vivem sob a influência de uma lógica empresarial que implica a proteção da propriedade pelo sistema das patentes; os recursos financeiros de nossos governos subsidiam essas bioindústrias, sobretudo na fase de implantação e de início das empresas, que exige grandes investimentos para a criação de plataformas biotecnológicas e construção de centros de pesquisa. Nossos governos intervêm ainda, e frequentemente, quando a bioindústria vai mal. O Canadá e o Quebec voltaram-se claramente, em todas essas áreas, para o neoliberalismo: aqui a filosofia econômica que prevalece considera de fato a livre-troca e seu corolário, a liberalização comercial em escala mundial, como a via real para o crescimento econômico do país e para o pleno emprego. As considerações ambientais passam para o segundo plano em nosso país e em outros países do mundo.

Governos, instituições financeiras, estabelecimentos públicos de pesquisa, empresas privadas e sindicatos se deram as mãos, com rara unanimidade, para aplicar ao mundo da bioeconomia o famoso "modelo quebequense", baseado em um intervencionismo planejado do Estado, um modelo cujo impacto é reforçado pela proximidade geográfica deste gigante das biotecnologias, os Estados-Unidos, pelas formidáveis possibilidades de comércio oferecidas pelo Acordo de Livre-Comércio da América do Norte (NAFTA) e pelos acordos que regulamentam o comércio 
internacional, os quais favorecem amplamente o Canadá e o Quebec. No "modelo quebequense", o Estado se comprometeu a subsidiar, entre outros, através dos investimentos de sociedades estatais como a Société Générale de Financement (SGF) e a Caisse de Dépôt et Placement (CDP) da Província do Quebec, as áreas julgadas mais promissoras da "nova economia", ou seja, as biotecnologias, a multimídia e o comércio eletrônico - setores que o governo quebequense faz questão de consolidar para reforçar sua competitividade nacional, continental e mundial.

Para cooptar os líderes políticos, os banqueiros e industriais, os governos, as universidades e o grande público, os promotores da bioindústria acenam para as extraordinárias repercussões financeiras para os primeiros países a implantar plataformas tecnológicas de ponta, mesmo que dispendiosas, para aqueles que tiverem construído centros especializados em $P \& D$ nas biogenonanotecnologias e que tiverem proporcionado condições vantajosas de instalação (isenções fiscais, créditos de impostos) às bioindústrias. Eles destacam a magia das poderosas máquinas de decodificação do genoma, vangloriam as proezas de seus softwares de bioinformática e a rapidez dos robôs autômatos, hoje instalados em suas plataformas de pesquisa. Se quisermos nos impor mundialmente, há urgência em agir, dizem os promotores da bioindústria, que sonham se tornar líderes em uma economia cada vez mais globalizada com o apoio dos fundos públicos. Quando se entra no universo das tecnociências, todo o discurso em torno do desenvolvimento sustentável parece ter sido esquecido.

Os promotores da revolução da engenharia genética prometem também, entre outras coisas, dentro em pouco, tratar melhor de nossas doenças, de modo diferente, na própria origem, com menos efeitos secundários do que no passado. Essa retórica do sucesso, um tanto fácil, compulsiva, acabou sem dúvida entusiasmando os políticos mais céticos, que dão seu apoio às bioindústrias. Por que nossos governos aceitam investir, por meio 
de isenções fiscais, de apoio maciço à $\mathrm{P} \& \mathrm{D}$ e de outros generosos programas, tanto dinheiro dos contribuintes nas bioindústrias? Seria simplista explicar esse intervencionismo estatal só pelo lobby dos industriais: na realidade, é o prestígio de uma ciência de ponta, as repercussões anunciadas da P\&D em medicina, em agricultura, no ramo bioalimentar e a utopia que os líderes políticos financiam quando sustentam a bioeconomia.

\section{A formidável "impressão ecológica" do século XX}

Em 1930, o americano Robert Millikan, prêmio Nobel de física, afirmava que não havia nenhum risco de que os seres humanos pudessem deteriorar algo tão gigantesco quanto a Terra. Setenta anos mais tarde, o historiador John R. McNeill (2001) sustenta que o século XX parecerá excepcional às gerações futuras não em razão das guerras mundiais, do nazismo ou do comunismo, mas muito mais devido às mudanças destrutivas consideráveis que o homem terá causado ao planeta nesse século. No livro escrito por McNeill, um dos maiores especialistas em história ambiental, o leitor descobre, um tanto perplexo, a amplitude da "impressão ecológica", que ele considera mais profunda do que aquela deixada na Terra por todas as gerações passadas e, ao mesmo tempo, o vasto panorama das transformações intensas que nosso planeta sofreu ao longo do século (ver resenha feita por Mouhot, 2009).

McNeill chegou a quatro conclusões que guiam esta reflexão: "Primeiramente, o século XX é excepcional pela intensidade de suas mudanças e pelo papel central desempenhado pela humanidade". Em outras palavras, as sociedades humanas são responsáveis pela degradação do planeta. "Em segundo lugar, essa particularidade ecológica é a consequência inesperada de preferências e de modelos de ordem social, econômica e intelectual". Ou seja, o estilo de vida adotado pelas sociedades industriais produziu, 
com o tempo, a situação em que nos encontramos hoje. "Em terceiro lugar, nossos modos de pensamento, nossos comportamentos, a produção e o consumo são adaptados às circunstâncias presentes, isto é, às condições climáticas atuais, à abundância típica do século XX - energia e água doce baratas, crescimento rápido da população e mais ainda da economia". Em outros termos, vivemos, no decorrer do século passado, fenômenos de crescimento em um contexto de abundância que nos deixou cegos aos efeitos destrutivos de nossos comportamentos. "Em quarto lugar, seria difícil mudar essas preferências e modelos se as circunstâncias mudassem", o que significa dizer que as sociedades não mudam facilmente os valores que fundamentam suas maneiras de viver e de pensar.

$\mathrm{O}$ autor aprofunda, em seguida, os debates que agitam atualmente a esfera política, salientando que um número cada vez maior de cidadãos está mais consciente, na maioria dos países, dos perigos que corre nosso planeta se continuarmos a viver como agora. Ele também observa que os especialistas em Ciências Sociais ignoraram, durante muito tempo, o lugar do meio ambiente na vida das pessoas e que só muito recentemente começaram a levá-lo efetivamente em conta em seus trabalhos sobre as sociedades. Podemos nos interrogar como pudemos ser tão míopes durante tanto tempo e como, por assim dizer, não percebemos nada e só descobrimos a necessidade de estudar nosso meio ambiente no momento em que a catástrofe quase inevitável tornou-se uma evidência para todos.

De maneira geral, as Ciências Sociais conceberam a evolução de nossas sociedades como uma longa e incessante complexificação dos modos de organização social, política e econômica. Essa ótica deveria ter levado os especialistas das sociedades, ao que me parece, a destacar o impacto que os valores e os estilos de vida que prevaleciam em nossas sociedades exerceria sobre nossos ecossistemas. Eles precisaram ver o aparecimento recente das sociedades capitalistas avançadas, descritas como fundamen- 
talmente consumidoras, predadoras e ávidas de recursos e destruidoras da "natureza", para repentinamente se dar conta de que os ecossistemas estavam em perigo e de que as sociedades corriam o risco de enfrentar graves crises ambientais. Para alguns deles, era claro que se preparava uma catástrofe de grandes dimensões, enquanto outros continuavam a pensar, com toda tranquilidade, que os perigos eram exagerados e que nossas opulentas sociedades podiam continuar a viver como outrora.

Urge que os especialistas do estudo das sociedades ultrapassem essas duas visões caricaturais e que se inicie um diálogo entre os defensores desses pontos de vista antagônicos, entre os otimistas - convencidos de que a ciência pode resolver os problemas levantados - e os pessimistas, com frequência alarmistas e militantes, sem dúvida por querer despertar seus colegas adormecidos. Mais do que a Sociologia, a Antropologia se mostrou atenta às questões ambientais e ao estudo das relações entre populações e meio ambiente, provavelmente devido à importância que a Antropologia clássica atribuiu aos modelos oriundos da ecologia cultural, às pesquisas sobre a longa duração da evolução humana e às comparações entre as sociedades em escala mundial (Bibeau, 2004).

A crer no historiador John McNeill, as diferentes disciplinas, da Geografia à Sociologia, da Economia às Ciências Políticas e à Antropologia, passando pela Biologia e Ecologia, devem trabalhar juntas se quisermos avaliar verdadeiramente as mudanças que o homem causou, e ainda causa, na natureza e na biosfera, isto é, em todos os meios em que a vida existe. Ao longo do século XX, nosso estilo de vida deixou uma "impressão ecológica" que marcará o planeta nos séculos futuros: erosão dos solos devido ao uso constante de adubos artificiais; poluição do ar provocada pela combustão intensa de energias fósseis; redução da camada de ozônio provocada pelos produtos modernos (aerossois, refrigeradores, etc.); diminuição das fontes de água potável; mudança climática em todas 
as latitudes; retrocesso das geleiras alpinas; diminuição da biodiversidade (Wilson, 2006) e tantos outros problemas ecológicos, agora tão evidentes que não podem mais escapar ao nosso olhar a menos que sejamos mal informados ou que tenhamos má vontade.

Ecologistas, biólogos, economistas, cientistas políticos, sociólogos e antropólogos devem de agora em diante trabalhar juntos para estudar como as sociedades humanas, principalmente as sociedades tecnicamente avançadas, transformam seu ambiente com suas maneiras de viver e modos de exploração dos recursos. A abordagem interdisciplinar se impõe tanto mais porque logo seremos 7 bilhões de seres humanos no planeta e porque países como a China e a Índia, que somam mais de 2,5 bilhões de habitantes, poderiam adotar um estilo de desenvolvimento bastante semelhante àquele que os ocidentais escolheram ao longo do século XX.

\section{Quem ainda pode negar as mudanças climáticas?}

No início de 2009, os especialistas do Grupo Intergovernamental de Especialistas sobre a Evolução do Clima (GIEC) constataram que as emissões mundiais de gás de efeito estufa estavam aumentando mais depressa do que haviam previsto. Foram assim obrigados a rever suas previsões referentes ao aumento das temperaturas mundiais até 2100. Em 2007, o GIEC havia considerado uma variação bastante ampla - entre 1,10 C e 6,4 o $\mathrm{C}-$, mas agora acredita que se deveria prever aumentos maiores de temperatura (Désaunay, 2009).

Mais recentemente ainda, foram os especialistas do MIT que revelaram previsões mais alarmantes para o ano de 2100 (Chandler, 2009). Esses pesquisadores elaboraram um modelo informático que se diferencia daquele do GIEC, principalmente por ser capaz de considerar o impacto das atividades humanas sobre o aquecimento do planeta, utilizando indi- 
cadores como a taxa de crescimento econômico e o consumo de energias fósseis nos diferentes países do mundo. Segundo esse modelo, se a escalada de emissões mundiais de gases de efeito estufa prosseguir, o aumento de temperatura poderá alcançar 5,20 C em 2100. É então provável (90\%) que o aumento médio das temperaturas fique entre 3,5ㅇ e 7,4으 $\mathrm{C}$. O impacto de um aumento de 3 graus nas temperaturas médias já teria efeitos catastróficos: mais de 3 bilhões de pessoais ficariam sem água; a malária atingiria vastas regiões onde já foi erradicada; as costas de inúmeros países seriam inundadas, etc. (Dossiê Le Climat, Questions Internationales, 2009).

Entretanto, em um cenário otimista que implicaria a implementação ampla de políticas muito ambiciosas de redução para lutar contras as emissões de gases de efeito estufa, o aumento médio das temperaturas mundiais poderia se aproximar de 2,5으. $\mathrm{C}$. Resta saber se tal cenário é de fato realizável. Enquanto a conferência de Copenhague de dezembro de 2009 determina o futuro do protocolo de Kioto após 2012, o envolvimento das maiores potências mundiais ainda permanece relativamente tímido. É verdade que todos os planos de retomada das maiores economias mundiais atribuem um lugar inédito à economia "verde", principalmente às energias renováveis, mas não operam, entretanto, uma virada radical. Segundo um estudo do HSBC, a União Europeia dedicaria 14\% de seu plano de retomada econômica às mudanças climáticas e ao investimento nas energias limpas (25 bilhões de euros); os EUA, um pouco menos de $10 \%$ do montante acumulado de seus dois planos de retomada principais (146 bilhões de dólares sobre 1 trilhão e 525 bilhões de dólares); a China, mais de um terço de seu plano (198 bilhões de dólares). O Canadá vem bem atrás.

A mensagem enviada pelo G8 (Estados-Unidos, Japão, Alemanha, França, Reino-Unido, Itália, Canadá e Rússia) na Cúpula de Áquila, em julho de 2009, é pouco reconfortante do ponto de vista ecológico. Os membros do Fórum das Principais Economias (ou seja, os países do G8, 
o G5 - formado pela África do Sul, Brasil, México, China e Índia - mais a Austrália, a Coréia do Sul e a Indonésia), responsáveis por $80 \%$ das emissões de $\mathrm{CO}_{2}$, se recusaram a se comprometer a reduzir à metade suas emissões de dióxido de carbono até o ano de 2050. Contentaram-se apenas em retomar a declaração do G8 no encontro de Áquila, segundo a qual "o aumento da temperatura média mundial não deve exceder $2^{\circ}$ C em relação ao nível pré-industrial".

Alcançar esse modesto objetivo implicaria, segundo o GIEC, que as emissões mundiais de $\mathrm{CO}_{2}$ diminuíssem de 15 a 30\% até 2020 em relação a 1990. Até hoje, somente a União Europeia se comprometeu a diminuir $20 \%$ de suas emissões entre 1990 e 2020 e a tomar o ano de 1990 como referência. Os outros países desenvolvidos propuseram objetivos menos ambiciosos até 2020: os EUA, diminuição de 17\% em relação a 2005 (ou seja, diminuição de 4\% no período 1990-2020); o Japão, diminuição de 15\% em relação a 2005; e o Canadá, novamente atrás (Chaon, 2009). De acordo com a revista Nature, se os países se limitarem a seus objetivos atuais e se os atingirem realmente, as emissões de $\mathrm{CO}_{2}$ dos países mais desenvolvidos diminuirão de 8 a 14\% entre 1990 e 2020, e as dos países em desenvolvimento, de $4 \%$ no mesmo período. A probabilidade de que o aumento das temperaturas mundiais seja superior a 2\% até 2020 ultrapassaria então os $50 \%$.

Para que objetivos mais ambiciosos em termos de redução de emissões de $\mathrm{CO}_{2}$ sejam fixados e respeitados, é crucial a questão do financiamento estatal. Alguns países em desenvolvimento julgam que seria normal que os países mais desenvolvidos, os maiores emissores de $\mathrm{CO}_{2}$ e mais ricos, dedicassem mais recursos financeiros à luta mundial com o aquecimento climático. O porquê da ideia do presidente mexicano, Felipe Calderón, de criar um "Fundo verde mundial", alimentado por todos os países do mundo (exceto os mais pobres) em função de seus níveis de 
emissão. Se essa proposta fosse aceita por todos os Estados, restaria determinar o montante dos fundos pagos e redistribuídos, o que poderia ser um dos temas da Cúpula de Copenhague. Não foi o que aconteceu nesse encontro, cujos resultados foram muito decepcionantes.

\section{Conclusão: Somos os últimos homens?}

Nossa responsabilidade em relação à vida somente poderá se exercer, no futuro, mediante duas condições: de um lado, a humanidade deverá assumir, numa civilização cada vez mais biotécnica, uma relação crítica com seus instrumentos técnicos e seu poder de transformação dos seres vivos em seu meio; de outro lado, ela deverá formular um novo humanismo estruturado mais em torno das noções de vida e de ecologia do que de matéria; um humanismo mais ancorado nas ciências da vida do que naquelas da matéria, ou tanto quanto; um humanismo que deverá se difundir em toda a sociedade, entre os cientistas, entre os especialistas das Ciências Sociais e na população em geral. Esse novo humanismo somente ajudará o homem a "cuidar" da vida e de seu mundo se ele se abrir ao reconhecimento da pluralidade das formas de vida e, ao mesmo tempo, à diversidade cultural do mundo humano, das línguas, das religiões, das filosofias. Não bastará respeitar a diversidade dos seres vivos e das culturas, será necessário fazê-los frutificar, em uma responsabilidade concebida como um zelo, como um "cuidado".

A responsabilidade em relação à vida só poderá ser exercida pelo homem em solidariedade com todos os seres vivos dos quais ele é, mais do que provavelmente jamais suspeitou, parente próximo. Essa responsabilidade inclui também o respeito à biodiversidade tal como ela se manifesta nos múltiplos ecossistemas presentes na Terra. Talvez a solidariedade entre o homem e os seres vivos permita superar o conflito, já existente, 
entre os defensores de um ecologismo às vezes utópico e os promotores do poder das biotecnologias. Cultura biocientífica e pensamento pluralista serão sem dúvida, no futuro, os principais antídotos para proteger a humanidade contra todos os reducionismos, aqueles que banalizam a vida e a natureza afirmando que se pode transformá-las, mas também aqueles que a sacralizam a ponto de torná-la intocável, não transformável.

Yvan Illich escreveu, com propriedade, que o conceito de vida é o último bastião do humanismo científico moderno. Se a vida é banalizada, reduzida a uma mera teoria do gene e usurpada pela bioindústria, então todo um sistema de filosofia e de cultura cai na obscenidade e no vazio. A questão da definição do homem não se resolve absolutamente com a descoberta de que nosso genoma é composto de mais de 3 bilhões de bases e de que funciona como um software de computador. Se não retomarmos a ideia de que somos simultaneamente seres falantes e fabricantes de instrumentos, a humanidade poderá ter um fim trágico. Não devemos esquecer que a evolução não passa de um cemitério de espécies extintas após uma catástrofe cósmica, uma guerra entre as espécies ou, na maior parte das vezes, devido aos abusos em suas relações com o meio. Seríamos assim a primeira espécie a se ter autodestruído.

As más notícias da economia foram manchete dos jornais ao longo do último ano. Nosso edifício econômico parece subitamente ter sido construído sobre areia: a cupidez dos banqueiros e dos operadores de mercado, sustentada pela ideologia neoliberal do livre-mercado e de um Estado minimalista, provavelmente nos teria conduzido à catástrofe não fosse a intervenção maciça dos governos na maioria dos países do mundo. Os gurus da economia, inclusive aqueles que receberam um prêmio Nobel, continuam tentando nos explicar, sem nos convencer, as razões que os impediram de ver a aproximação da crise. Eles continuam sem saber nos dizer, aliás, por que exatamente ocorreu uma crise de tal amplitude. Confessam assim sua incapacidade para prever o que quer que seja. 
Concluindo, essa referência à crise bancária e financeira serve para lembrar a fragilidade das instituições que acreditamos assentadas em sólidas fundações. Talvez tenha chegado o momento de nos perguntarmos se uma catástrofe maior não está em vias de destruir o mundo em que vivemos. É hora de lançar um verdadeiro debate cidadão em torno dessa questão.

\section{Sustainable development "made in Quebec". Policies of environmental protection and biotechnology}

\section{Abstract}

To a certain extent, the technical-scientific advances have allowed us to "tame" nature. This essay examines the situation of the governmental environmental policies, especially that of the state of Quebec, which adopted the law of sustainable development in April 2006. In this line of argument, this article considers the changes in the context of the recent advances in biotechnology, which give us an unprecedented power over nature, life and human beings. The diverse forms of intervention, from the governments of Canada and Quebec, are indicative of an increase in the active presence of the State, not only in the traditional sectors, but also in the bio-industry, in which the government intervenes more and more. The challenges, consequences and issues of this reality will be addressed from the perspective of a new humanism.

Keywords: Quebec. Biotechnologies. Environmental policies. Humanism.

\section{Referências}

BIBEAU, Gilles. Les dérives de la bio-industrie. Relations (Numéro thématique. Technoscience: la boîte de Pandore, 734 (ago), p. 14-15, 2009 $2004 a$ . Le Québec transgénique. Science, marché, nation. Montréal: Boreal, . Entre génomythe et géno-destin. Les défis de la nouvelle médecine prédictive. Argument. Politique, société et histoire, 6, 2, p. 34-46, $2004 \mathrm{~b}$. 
. Géno-business made in Montréal. Possibles ( $\mathrm{n}$ o thématique: Montréal mégacité), 27, 1-2, p. 127-143, 2003.

CHANDLER, David. Revised MIT Climate Model Sounds Alarm. TechTalk, 53, 26, 20 mai 2009.

CHAON, Anne. Climat : engagements américains et canadiens pas à la hauteur pour Paris. Agence France-Presse, 2009.

CST (Conseil de la science et de la technologie). Plan d'action de développement durable 2008-2011. Québec : Conseil de la Science et de la Technologie, 2011.

DÉSAUNAY, Cécile. Réchauffement : plus rapide et plus intense. Futuribles, 351, abr, p. 85-86, 2009.

LA DOCUMENTATION FRANÇAISE. Dossier Le climat. Questions internationales, 38, jul-ago, p. 4-90, 2009.

MASLIN, Mark. Global Warming. Oxford: Oxford University Press, 2004. p. 2335.

McNEILL, John Robert. Diamond in the Rough : Is There a Genuine Environmental Threat to Security?. International Security, 30, 1, p. 178-195, 2005.

. Something New Under the Sun. An Environmental History of the 20thCentury World. New York : W.W Norton \& Co, 2001.

MOUHOT, Jean-François. Du nouveau sous le soleil. La revue internationale des livres et des idées, 11, mai-jun 2009, p. 4-10, 2009.

OCDE. The Bioeconomy to 2030. Paris : OCDE, 2009. 326 p.

SALOMON, Jean-Jacques. L'impérialisme du progrès. Écologie \& Politique, 31, p. 137-143, 2005. 1999.

. Survivre à la science. Une certaine idée du futur. Paris: Albin Michel,

VIDAL, Jean-Michel; BIBEAU, Gilles. Les médicaments sous la coupe d'une logique marchande. In : GARNIER, Catherine; LÉVY, Joseph J. (Directeurs). Médicaments. De la conception à la prescription. Montréal: Liber, 2009. p. 127-145.

WILSON, Edward O. The Creation. An Appeal to save Life on Earth. New York and Londres: W.W. Norton \& Cpy, 2006. p. 37-69.

Recebido: $15 / 09 / 2010$

Aceite final: 19/10/2010 